\title{
Demystifying Trends and Future Implications of Cardiovascular Disease Burden in India. From Rhetoric to Reality and Policy to Action by Targeting Social Determinants of Health to advance Health Equity and Reduce Global Disease Burden
}

\author{
Manish Barman ${ }^{1 *}$, Palak Barman ${ }^{2}$ \\ ${ }^{1}$ Hamad Medical Corporation, PO Box 3050, Doha, QATAR \\ ${ }^{2}$ DPS MIS Economics, QATAR \\ *Corresponding Author: drbarman@yahoo.com \\ Citation: Barman, M. and Barman, P. (2018). Demystifying Trends and Future Implications of \\ Cardiovascular Disease Burden in India. From Rhetoric to Reality and Policy to Action by Targeting Social \\ Determinants of Health to advance Health Equity and Reduce Global Disease Burden. European Journal of \\ Environment and Public Health, 2(2), 09. https://doi.org/10.20897/ejeph/3924
}

Published: October 7, 2018

\begin{abstract}
Socioeconomic determinants of health assume great significance in Indian context due to its diversity. We aim to appraise the current national level health initiatives aimed at decreasing the cardio vascular disease (CVD) burden in India in context with established conceptual frameworks for advancing integrated health and value-based care. Literature review for interpretive and qualitative observational analysis was undertaken to assay various healthcare constructs affecting health policy formulation and implementation. Indian research has focused on risk prevention aspects of CVD rather than risk behavior modification through policy implementations. Future interventions should focus on formulating ingenious strategies to get a grip on crucial social challenges to translate gains in measurable units involving all stakeholders. Our study elaborates and enumerates various measures undertaken by the government of India (GOI) till date for CVD risk reduction. Future effective public-health interventions in India must incorporate complex socioeconomic measures to confront major elements of health inequalities.
\end{abstract}

Keywords: health policy, cardiovascular disease, social determinants of health

\section{INTRODUCTION}

Cardiovascular diseases today are one of the leading causes of mortality and morbidity in India (Prabhakaran and Jeemon, 2016). Statistics show the average age standardized cardio vascular disease (CVD) death rate in India is 272 per 100000 people and is far above the world average of 235 (Prabhakaran and Jeemon, 2016). Growing economic healthcare burden necessitate innovative intervention policies to reduce CVD burden and promote heart health through community-based services. Demographic shifts, lifestyle changes from urbanization and globalization, altered age profiles, fetal and childhood undernutrition, genetic environmental susceptibility in diverse strata are leading India to a state of rapid health transition where CVD burden is fueled by change in diet, reduced physical activities and incremental tobacco use (Glymour et al., 2014). Since level of inequalities change over time and socioeconomic determinants have an increasing role in CVD burden, this brings in a ray of hope that emphasis on targeted policies and intercessions through socioeconomic determinants of health may be an important tool for reduction in the CVD burden in India (Glymour et al., 2014). 


\section{What causes the most deaths?}

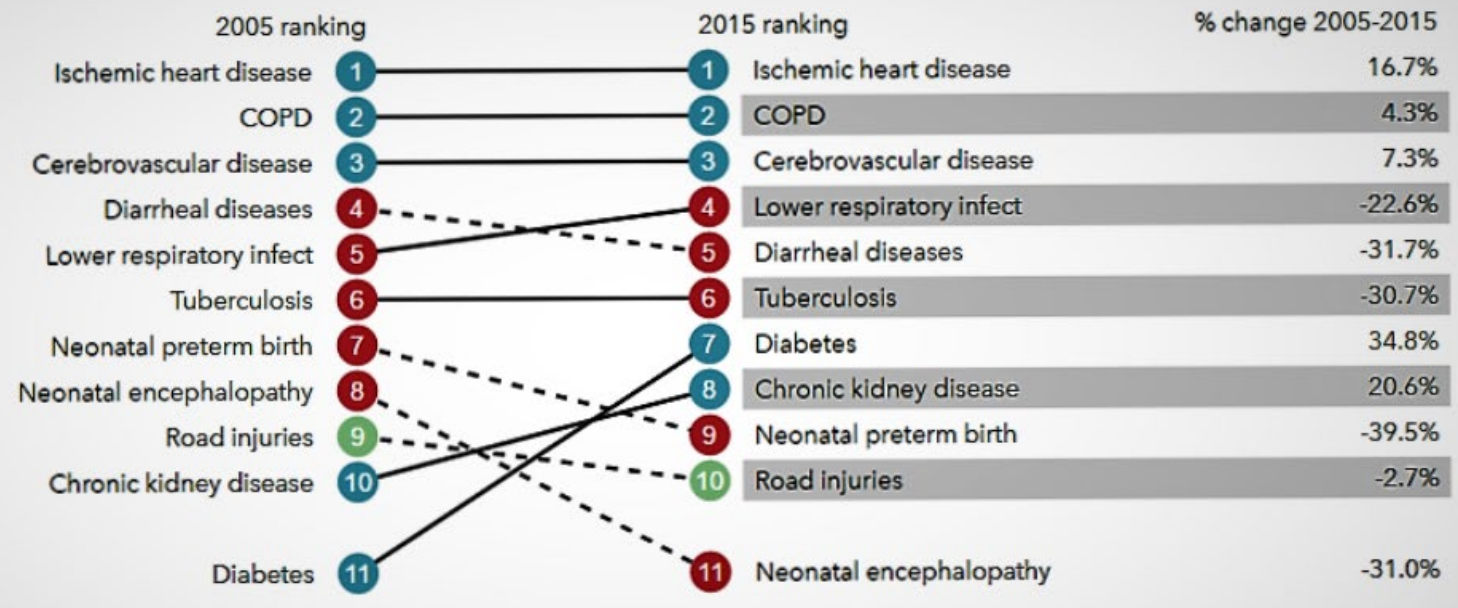

Top 10 causes of death by rate in 2015 and percent change, 2005-2015

Figure 1A. Institute for Health Metrics and Evaluation (2017). University of Washington; country profile India (www.healthdata.org/india)

Forestalling the epidemic requires local malleability and adaptation, innovative strategies, evidence-based practices and policies and enhancing health systems with focus on prevention, early detection and continuous evaluation (Prabhakaran and Jeemon, 2016). Fragmented Indian policies and state initiatives marred by lack of comprehensive data makes it difficult to highlight the impact of CVD on national economy and undermines every effort of increased healthcare spending. Policymakers with clear understanding of the complexities of CVD burden can steer strategic plans, focusing on priority areas to translate into desired future outcomes (Prabhakaran and Jeemon, 2016).

\section{Growing CVD Burden}

Since independence, India has had its focus on reducing the burden of malnutrition, maternal and childhood ailments and infectious diseases (Prabhakaran and Jeemon, 2016). With significant success on various fronts it has witnessed a huge epidemiological transition in the last two decades towards non-communicable diseases (NCDs) which is growing by the decade (Prabhakaran and Jeemon, 2016; Bloom et al., 2011). Institute of Health Metrics and Evaluation reports that CVD rose from its 8th ranking in 1990 to the 4th most important reason of premature mortality in 2010 (IHME, 2017). The prevalence of CVD was $2 \%$ in urban regions and escalated 7 -fold to $\sim 14 \%$ by 2013 (Engelgau and Mahal, 2014). Top 10 causes of death by rate in 2015 and percentage change, 2005-15 as reported by Institute of Health Metrics and Evaluation for India are depicted in Figure 1A, whereas combined death and disability causes are depicted in Figure 1B.

This escalating CVD burden mirrors numerous risk factors, including, absence of information, bad dietary habits, increased tobacco and liquor utilization, diminishing physical activities, increasing central obesity, untreated lifestyle diseases like diabetes mellitus, hypercholesterolemia, elevated blood pressure and prolonged life span (Popkin et al., 2001; Reddy and Katan, 2004; Prabhakaran et al., 2005; Goyal and Yusuf, 2006). This further translates into an augmented fiscal burden (Mahal et al., 2010; Bloom et al., 2011; Leeder et al., 2004; Gupta et al., 2006). Contemporary research indicates that cardio vascular related cumulative health care cost was around US\$3 billion in 2004 (Mahal et al., 2010) and US\$7.5 billion in 2010 (Bloom et al., 2011). Leeder et al. (2004) and Gupta et al. (2006) had projected significant fiscal loss due to cardio vascular burden and labor losses. CVD burden has, in terms of premature mortality, expanded by an alarming 59\%, from 23.2 million to 37 million in last decade (Chauhan and Aeri, 2015). Figure 2 portrays the vicious cycle of poverty and non-communicable diseases (NCD's) in low and middle-income countries (LMICs) (Global status report on Noncommunicable diseases, 2010). Socio economic determinants and the complex underlying dynamics of loss in production and lack of strategies only propagate it further. Today the need is to research, practice and formulate policies to tackle these wider social determinants of health, through the implementation of appropriate interventions, and thereby reducing the gradient and health inequalities (Global status report on Noncommunicable diseases, 2010). 


\section{What causes the most death and disability combined?}

Communicable, maternal, neonatal, and nutritional diseases

Non-communicable diseases

Injuries

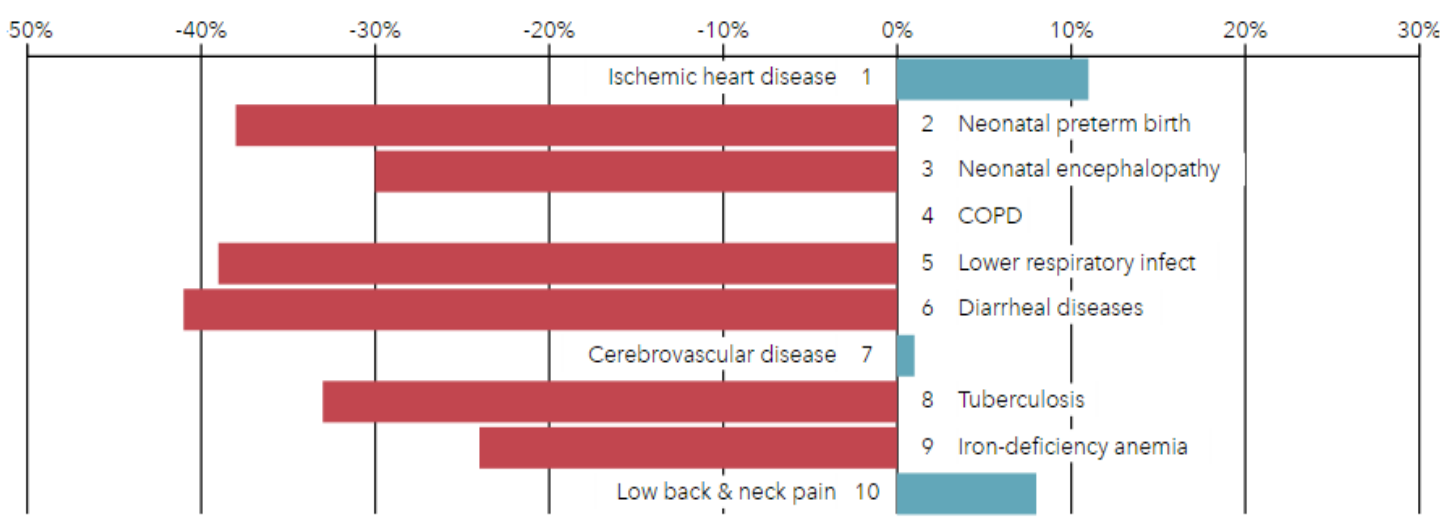

Leading causes of DALYs in 2015 and percent change, 2005-2015

Figure 2B. Institute for Health Metrics and Evaluation (2017). University of Washington; country profile India (www.healthdata.org/india)

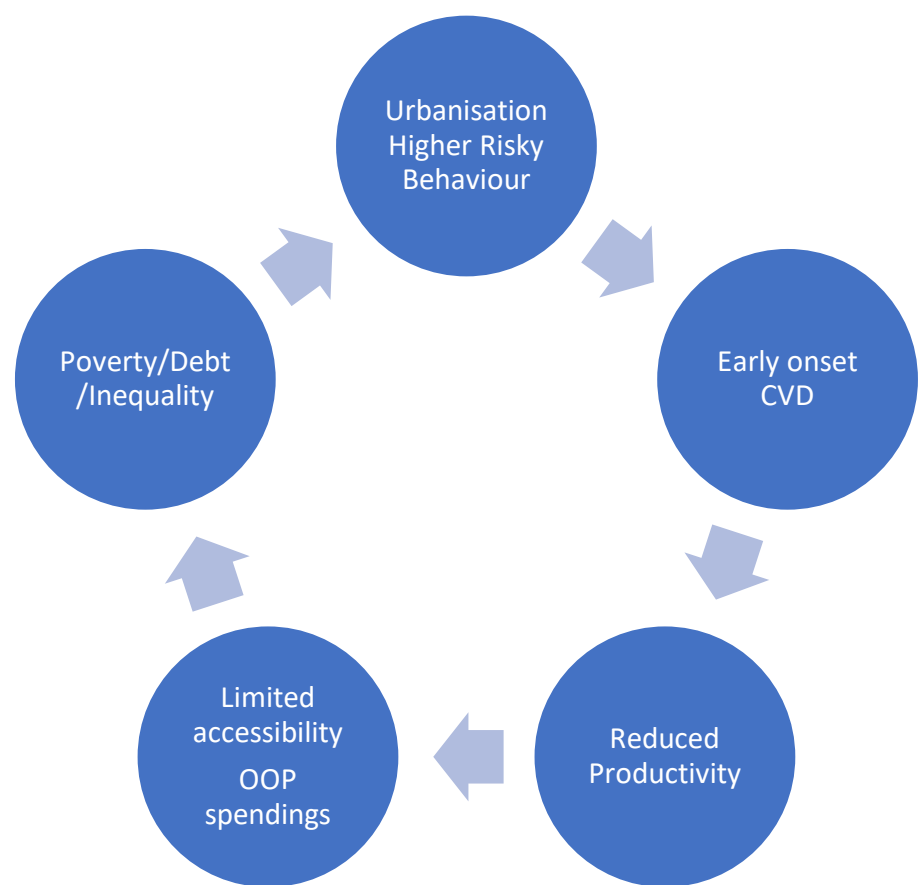

Figure 2. The vicious cycle of poverty and NCDs in LMIC. WHO: Global status report on Noncommunicable diseases (2010)

\section{The Argument for Policy Prioritization}

Since apparent diseases and their direct causal agents are easy to identify and treat, both policy makers and practicing physicians have traditionally shied away from the more complex social determinants to be studied and implemented into policies for direct interventions (Chauhan and Aeri, 2015). As India undergoes rapid health saltation due to economic growth and stable political environment predicted for next decade, the disparity between healthcare needs and resources will be widened by the health conditions that compete for policy maker's attention (Chauhan and Aeri, 2015). The intricacies get knottier when policy must be graded on disease burden, cost effectiveness, accessibility and equity while delivery systems simultaneously grapple with the heightened pressures of economic reconstitution and healthcare reforms (Chauhan and Aeri, 2015). CVD burden exemplifies the 


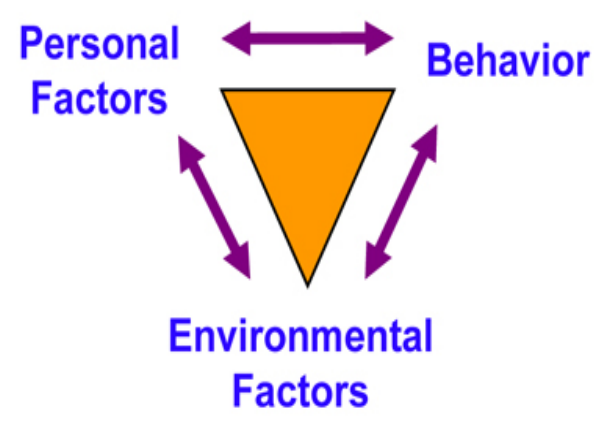

Figure 3. SCT dynamics as explained by Albert Bandura (Bandura, 2002)

enormous investments that will obtrude on healthcare systems by incremental midlife morbidity and mortality (Glymour et al., 2014; Prabhakaran et al., 2013; Reddy, 2002). It is, therefore vital to embrace the dynamics of CVD epidemic and guide public health responses towards alleviating this major, mostly preventable disease burden in terms of lost DALYs (Murray and Lopez, 1997; Reddy and Yusuf, 1998).

\section{METHODS}

This research undertakes literature review-based methodology for interpretive and qualitative observational analysis. Interpretation and synthesis of the current available literature mainly through electronic search was carried out for critical analysis and achieving the objectives of the research. Review of relevant literature data up to 01/April/2016 in English language available on PubMed, Web of science, Indian citation Index and Google scholar was undertaken. The keywords targeted were "coronary artery disease, "cardiovascular disease, "heart disease," "India, "burden, "prevalence" and "trends" to access English language articles for analysis. Reports of organizations such as World Health Organization (WHO), Institute of Health Metrics and Evaluation (IHME), were also studied to project the data. GOI policies were enumerated through official GOI websites, "National Commission on Macroeconomics and Health" (NCMH), "Centre for Chronic Disease Control" (CCDC), "National Health Portal of India" and "Ministry of Health and Family Welfare" (MoHFW) - GOI.

\section{Conceptual Framework}

The conceptual framework implied in this research relate to a multidisciplinary approach that involves in various healthcare constructs and which affect health policy formulation and implementation towards providing an integrated, value-based healthcare with respect to low and middle-income countries; and their limited financial resources in context with regional socio-economic determinants of health. This research applies 'Social cognitive theory' (SCT) developed by 'Albert Bandura' (Bandura, 2002; Bandura, 2004) to advance understanding of health risks and benefits of different health practices, towards formulating policies for promoting health interventions using social tools in India (Figure 3).

This research also provided an opportunity to explore our understanding of 'Precede-Proceed' model, which is a cost benefit evaluation framework by 'Lawrence W Green' guiding health policy makers in designing and implementation process (Green and Kreuter, 2005; Green and Kreuter, 2015), in Indian context of health policy making addressing social determinants of health (SDOH). Such understanding is closely related to the clinical manifestation of disease and Health related quality of life (HRQOL- graphically depicted in Figure 4) and should form the basis of developing governmental policies in achieving the desired targets. A systematically planned implementation of interventions enables better allocation of resources, optimization of results by improving and promoting health in democratic and participatory ways (Green and Kreuter, 2005; Green and Kreuter, 2015; Porter, 2016).

The uniqueness of this approach is also to understand the integration of world health organization (WHO) conceptual frameworks "WHO Package of Essential Noncommunicable disease interventions (WHO PEN)" (World Health Organization (WHO), 2010; World Health Assembly (WHA), 2008; WHO Framework for Action, 2007), and "Health in All Policies (HiAP) Framework for Country Action" (WHO, 2014) in Indian policies and health system for fundamental validity, liability, clarity, information gathering, credibility, and partnerships across various government departments aimed at improving outcomes against major NCD's. 


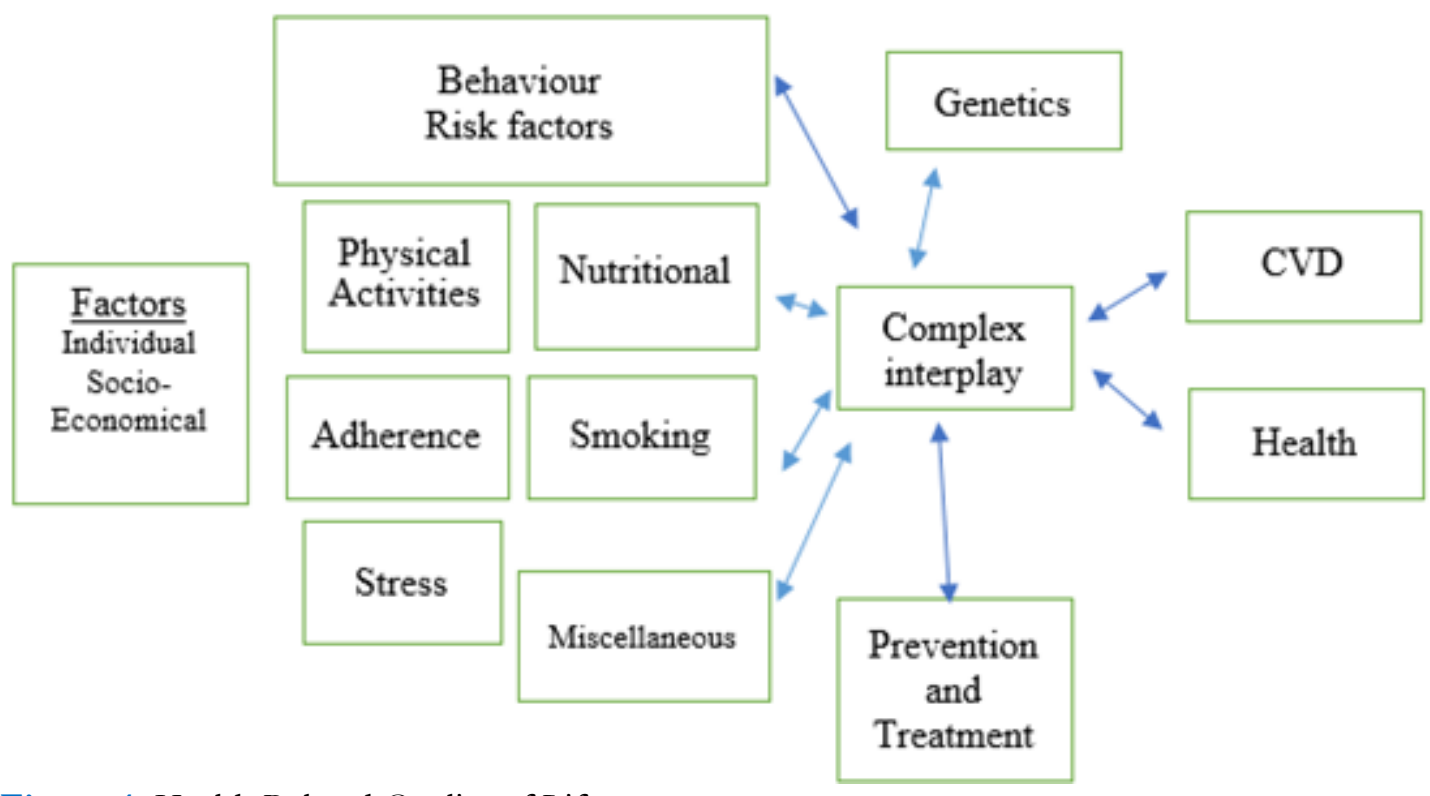

Figure 4. Health Related Quality of Life

No. in Millions

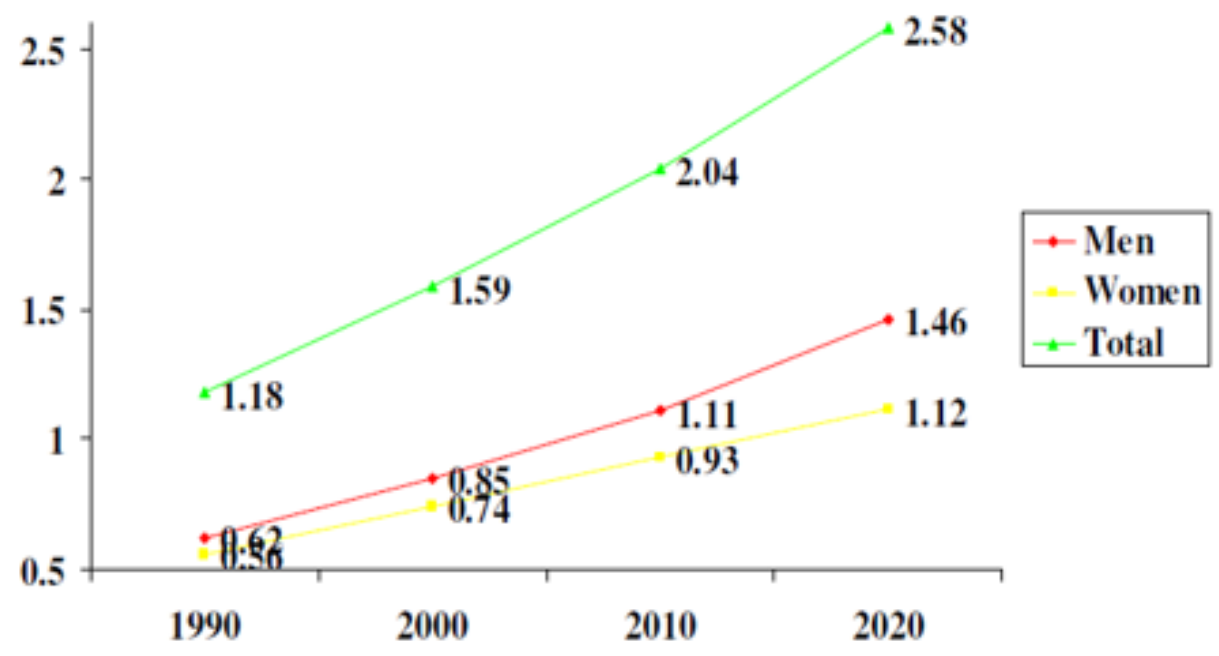

Figure 5. Projections for CVD mortality in India. Global Burden of Diseases Study (Ghaffar et al., 2004; BMJ, 2004)

\section{DATA COLLECTION AND ANALYSIS}

\section{Prevalence and Future Trends: National}

With approximately 3\% overall prevalence there were 29.8 million people diagnosed with CVD out of 1 billion Indian population in the year 2000 (Census of India, 2001; Gupta et al., 2000). This increased to about 4\% (rural) and 10\% (urban) in various cross-sectional surveys in 2003 (Ghaffar et al., 2004; Gupta, 2004) and 6\% and 12\% respectively in 2008 (Enas et al., 2009). Figure 5 shows projections for CVD mortality in India as per Global Burden of Diseases Study (Ghaffar et al., 2004). Further studies in 2013 revealed urban prevalence of $\sim 14 \%$ and rural prevalence at $\sim 7.4 \% 5$ depicting an alarming rate of epidemic proportions. CVD mortality rates in India (age standardized) were estimated by WHO in 2011 at 363-443(males) and 181-281 (females) (WHO, 2011). WHO statistics on Noncommunicable diseases (NCDs) estimates $53 \%$ of the total deaths in India to be related to NCDs with 24\% attributable to CVD (WHO, 2011). NCMH forecast predicts doubling of figures in prevalence percentage for urban population (20-29 Years) from year 2000 to 2020 indicating younger age of escalation of CVDs (Indrayan, 2005). Despite being lower than urban zones the CVD prevalence rates in rural zones could go 
as high as $13.5 \%$ (age group 60-69 years), compared to 22\% prevalence in urban zones (Mahal, 2005; Gupta and Gupta, 2009).

\section{Socioeconomic Status and Risk Factors in India}

Socioeconomic conditions and the altered demographic patterns which influence the living habits are a major driving force for the CVD epidemic in India (Yusuf et al., 2004). Preventive interventions can be based on principles of established risk factors reduction worldwide with potential to reduce CVD burden in any society (INTERHEART Study) (Yusuf et al., 2004). Major risk factors and behaviors for CVD like tobacco use, reduced fruit and vegetable consumption, high fat intake, obesity and metabolic syndrome, all have repeatedly shown a social gradient pattern with poorest rates in lower socioeconomic strata (Giovino et al., 2012; Indian Council of Medical Research, 2017; Sachdeva et al., 2013; Dhaka et al., 2011). ICMR INDIAB study (Mohan, 2017), has shown low education and socio-economic status (SES) as an important contributor to this effect (Mohan, 2017). Prevalence of hypertension is expected to double by 2025 (Danaei et al., 2011). Diabetes mellitus has practically multiplied in the urban region in the last 20 years from $9 \%$ to $17 \%$, and from $2 \%$ to $9 \%$ in rural regions (IDF Diabetes Atlas, 2017). Investigators of Prospective Urban and Rural Epidemiological study (PURE) (Chow et al., 2013) implicated that low academic caliber relates to diminished hypertension perception and management. Psychological stress associated with migration and urbanization not only affect contemporary cardio vascular (CV) risk factors but also promulgate risk behavior and practices (smoking, fad diets etc.) along with heightened inflammatory responses promoting CVD burden (Gupta et al., 2012; Gupta and Gupta, 1998; Braveman and Tarimo, 2002). Stress, deprivation and unsafe poor living conditions along with early life influences are all related CVD risk among low SES class in India (Chandola, 2001; Kutty et al., 1993; Vasan and Thomas, 2012).

\section{Socioeconomic Status and Risk Factors in India}

Socioeconomic conditions and the altered demographic patterns which influence the living habits are a major driving force for the CVD epidemic in India (Gupta and Gupta, 2009). Preventive interventions can be based on principles of established risk factors reduction worldwide with potential to reduce CVD burden in any society (INTERHEART Study) (Yusuf et al., 2004). Although national level data for major risk factors (except for tobacco) are not available in India, data from several large cross-sectional surveys are available and are presented.

\section{Tobacco Use}

It is estimated that, at present one in three person ( $>15$ years of age) uses tobacco in India with rates varying from 9\% to 67\% among states (Giovino et al., 2012). The mortality rates due to tobacco use in India are high and responsible for almost 1 million premature deaths annually (Lal et al., 2012). Experimentation with tobacco begins relatively early in India (Reddy et al., 2006) and is rising rapidly amongst youth (20-35 years) (Bhan et al., 2012), with significantly higher percentage in people with lower education (Gupta et al., 2003).

\section{Fruit and Vegetables Consumption}

Despite being largely a vegan society, regular fruits and vegetables consumption is low in India. The National Family Health Survey 3 (2017) showed that almost $50 \%$ of study population consumed zero or just one serving of fruit in seven days. It also reported a social gradient in consumption patterns with lowest rates in lower socioeconomic strata (Ramachandran, 2006). In addition, the vegetables consumed are mainly overcooked in Indian meals, leading to loss of food value (Indian Council of Medical Research, 2017; Sachdeva et al., 2013).

\section{Fat Intakes}

From 1972 to 2009, despite overall calorie intake remaining unaltered, the total fat intake increased in both rural and urban population from 24 to $36 \mathrm{gms} /$ day, and 36 to $50 \mathrm{gms} /$ day respectively (Ramachandran, 2006). Consuming high trans-fat as hydrogenated vegetable oil is rampant in city slum inhabitants (Dhaka et al., 2011; Misra et al., 2001). Multiple epidemiological studies show a rapid deterioration of lipid profile (Gupta et al., 2008). In the ICMR INDIAB study (Joshi et al., 2014), low education and SES were important contributors to this effect (Joshi et al., 2014).

\section{Physical Activity}

Scientific data on physical activity is meagre in India due to absence of a legitimate evaluation model, which can assess both work and recreational physical activity in both genders (Bharathi et al., 2000). Work and daily chores involve main physical activity and most studies neglect or are unable to capture these activities (Bharathi et al., 2000; Gupta et al., 1994). Voluntary sports activities are remarkably more in high SES in India, however, work related activities are significantly more in lower socioeconomic classes (Gupta et al., 2003; Gupta et al., 1994). 


\section{Obesity}

With increasing propensity for consumerism, largescale changes in dietary patterns particularly in the urban populations have skyrocketed the obesity epidemic (Monteiro et al., 2004). This is due to increasingly available cheaper calorie dense foods. The 'Jaipur Heart Watch' (Gupta et al., 2012) reports significant increasing trends for obesity in low socioeconomic population like tobacco and arguably driven by business interests specially in LMICs (Misra et al., 2001; Eckel et al., 2005).

\section{The Metabolic Syndrome}

Metabolic syndrome represents a cluster of cardiovascular risk factors and is an important pathognomonic marker of future coronary heart disease risk. Despite lack of adequate number of studies, it is estimated that prevalence varies from $20-30 \%$ in males and $25-35 \%$ in females across urban population (Ramachandran et al., 2003; Gupta et al., 2004).

\section{Hypertension}

Prevalence of hypertension is estimated to be around 30\% (34\% urban and 28\% rural) (Anchala et al., 2014). This is expected to double by 2025 (Kearney et al., 2005). The average blood pressure across India has increased for the last two decades whereas it declined in most Western nations (Danaei et al., 2011). Data from the Prospective Urban and Rural Epidemiological study implied that low educational status is related with decreased hypertension awareness and management (Chow et al., 2013).

\section{Diabetes Mellitus}

Diabetes mellitus has practically multiplied in the urban region in the last 20 years from $9 \%$ to $17 \%$, and from 2\% to $9 \%$ in rural regions (Gupta et al., 2012). In 2013, the International Diabetes Federation reported 65.1 million Indian adults suffering from diabetes mellitus and this was projected to increase to 101 million by 2030 (IDF Diabetes Atlas, 2017; Anjana et al., 2011). Both awareness and treatment of diabetes remains low in rural areas.

\section{Psychosocial Stress}

Psychological stress is often a neglected factor in pathogenesis of CVD (Brunner, 2002). Migration and urbanization not only affect contemporary CV risk factors but also weigh in social and mental stress (Gupta and Gupta, 1998). Hardships and anxiety states can promulgate risk behavior and practices (smoking, fad diets etc.) along with homeostatic and neuroendocrine changes resulting in differentiated autonomic capacities, advancing metabolic diseases and heightened inflammatory responses promoting CVD burden (Gupta and Gupta, 1998; Braveman and Tarimo, 2002).

\section{Miscellaneous}

Stress, deprivation and unsafe poor living conditions along with early life influences are all related CVD risk among low SES class in India (Kutty et al., 1993; Chandola, 2001; Vasan and Thomas, 2012). Maternal malnutrition affecting in- utero growth has been postulated with high risk of CVD later in life (Tarry-Adkins and Ozanne, 2011). These associations affect cognition and educational performance leading to increased CVD prevalence (Victora et al., 2008).

\section{GOVERNMENT OF INDIA (GOI) HEALTH POLICIES AND INITIATIVES}

\section{Tobacco Control Legislation (National Tobacco Control Program, 2017)}

National Tobacco Control Cell (NTCC) at the MoHFW is responsible for National Tobacco Control Programme (NTCP) which was launched in 2007- 08, to accentuate the adverse effects of tobacco consumption and to expedite implementation of Tobacco Control Legislations. The focus areas for the NTCP are education and coaching along with communication of informational activities. Besides monitoring tobacco control laws, it also coordinates various school programs and activities at village panchayat levels. It also facilitates deaddiction facilities for social cognition (National Tobacco Control Program, 2017).

\section{National Programme for Prevention and Control of Cancer, Diabetes, Cardiovascular Diseases and Stroke (NPCDCS) (2017)}

Pilot phase of NPCDCS (NPCDCS, 2017) was launched on 4th Jan 2008. The NPCDCS intends to harmonize NCD intercessions within the national rural health mission (NRHM) framework (National Rural Health Mission, 2017) for augmentation of limited assets, viability of interventions and arrangement of consistent services to the consumer. It endeavors to create an extensive knowledge base amongst populace for primordial prevention, understanding and therapeutic strategies through merging with the other ongoing National health programs 
(National Tobacco Control Program, 2017; National Rural Health Mission, 2017; National Programme for Health Care of the Elderly (NPHCE), 2017) whilst promoting healthy lifestyle.

\section{National Programme for Health Care of the Elderly (NPHCE) 2010-11 (2017)}

It was launched in 2010-11 with the objective to facilitate social cognition and promote good eating habits, regular physical activities, tobacco cessation programs and stress management etc. through domiciliary visits by trained health workers. It also promotes training of healthcare workforce through other means using social and mass media tools, to publicize and disseminate knowledge amongst community.

\section{Establishment of Model Rural Health Research Units (MRHRUs) (2017) in the States 2013-14}

With an aim to constitute infrastructure at the outskirts for transfer of technologies to underdeveloped regions for reconstructing the quality of health services and to establish integration between researchers at central medical institutions, providers and the beneficiaries at community level, MRHRUs (2017) were established in 2013-14. This ensures dissemination of knowledge and infrastructure to the rural areas and exemplifies the diffusion theory of SCT.

\section{Grant-in-aid (GIA) Scheme for Health Promotion (2017)}

GOI approved the "Grant-in-aid Scheme for Inter Sectoral Convergence and Coordination for Promotion and Guidance on Health Research" (GIA, 2017) for period 2012-17, to strengthen research efforts within different agencies, non-government organizations (NGOs) and Industries. Under this Scheme, the Department of Health Research under MoHFW provides support in shouldering research activities to establish current knowledge gap to analyze existing health needs and transform into realizable gains in a cost-effective manner.

\section{Integrated Disease Surveillance Program (IDSP)}

"Integrated Disease Surveillance Program" (IDSP) (Integrated Disease Surveillance program, 2017) was originally started with the assistance of "World Bank" in 2004 and later expanded nationally on the lines of WHO formulated STEPwise approach to cover all regions and continues during 12th Plan (2012-17) under "National Health Mission" (NHM) (earlier known as National Rural Health Mission) (2017). Surveillance units in all states and "Central Surveillance Unit" (CSU) are integrated with the "National Centre for Disease Control, Delhi" for collection of data and provide tele and video conferencing facilities for emergency responses in case of outbreaks. The key objective of the programme is to strengthen and maintain decentralized laboratory-based IT enabled disease surveillance system to monitor disease prevalence and trends.

\section{Electronic Health Records (EHR) Standards - 2016 for India}

Ministry of Health and family welfare notified EHR standards (Electronic Health Records (EHR) Standards, 2017) by the healthcare providers with the objective to introduce a uniform system in 2013 which has been revised in 2016 in line with contemporary developments and in consultation with relevant stakeholders across the country. Further these records are to be synced with unique identification authority of India (UIDAI) Aadhar (Unique Identification Authority of India, 2017) linked demographic and biometric details. This measure promotes STEPwise surveillance and adheres to WHO PEN framework.

\section{DISCUSSION}

Viable strategy level changes need community acceptance through behavioral changes and health promotion. This evolution is overwhelmingly determined by socioeconomic progress. From the earlier 'National health policy' framed in 1983, GOI only formulated its next National policy in 2002 (NHP, 2002). Thereafter a series of strategic initiatives have been undertaken to curb the prevalence of NCD's and strengthen healthcare delivery. The decline in cardiovascular mortality can be achieved by population level changes in common risk factors and medical therapies. Modelling studies elaborate significant advantages of suitable tax arrangements on tobacco, sugary beverages and palm oil alone to decrease the weight of CVD. Strict implementation of Smoke free legislation and tobacco taxation together have the potential to avert $25 \%$ of myocardial infarctions (MI) and strokes (Unal et al., 2004; Capewell et al., 2000; Bandosz et al., 2012; Ford et al., 2007). In this context, the strategy of Government of India to increase the excise duty on tobacco items up to $72 \%$ and to impose another $5 \%$ tax on sugary beverages are both supportive and promising (Union budget 2014-2015, 2017).

To develop newer context specific and locally acceptable strategies, "Centre for chronic disease control", New Delhi (CCDC) (Centre for Chronic Disease control, 2017) which is a WHO Collaborating Centre for Surveillance, Capacity building and Translational Research in Cardio-Metabolic Diseases is exploring many options for cardiac care and rehabilitation, 
a) Developing and testing integrated, multi-factorial 'Cardiovascular Disease Risk Reduction Strategies' in South Asia (CARRS Translation Trial),

b) Effects of a yoga-based cardiac rehabilitation program (Yoga-CaRe) on cardiovascular health and

c) Simplified Cardiovascular Management (SimCard) Study, to research on the effects of locally relevant cardiovascular intercessions in India (Centre for Chronic Disease control, 2017).

These circumstantial and resource sensitive conventional approaches which are agreeable to regional communities are efforts in right direction.

By establishing a "National action plan and monitoring framework for prevention and control of NCD's", India has endorsed World Health Assembly vision and shown the intent to enhance existing capacity and achieve crucial targets for 2025 by aiming at 30\% relative rate reduction in consumption of both tobacco and salt (Ministry of Health and Family Welfare, 2017; Global Action Plan for the Prevention and Control of NCDs 2013-2020, 2017).

\section{Targeting Social Determinants of Health in India}

India endorsed WHO recommended tobacco control and MPOWER strategies (MPOWER Brochure, 2017) (monitor, protect, offer help, warn, enforce ban and raise taxes on tobacco) by enacting the Cigarette and Other Tobacco Product Act (COTPA, 2017). However, in the Indian context, implementation is a challenge. Gutka (chewable tobacco) and Bidi (hand rolled tobacco in leaves) are small scale and un-regulated industries, difficult to control and tax. There is no control over local breweries producing cheap illicit liquor and nonsmoking tobacco products usually run by local small-scale enterprises. Similarly advocating any strategies for lower salt consumption will remain a challenge because iodized salt is used for iodine supplementation to reduce goiter prevalence in India. Being largely a vegetarian society most of the food consumed is dairy related or deep fried, rich in trans fats. In absence of guidelines and mandatory nutritional labeling, special attention is required towards nutritional epidemiology because of multiple and diverse cultural practices and dietary habits. It surely is challenging to promote affordable and culturally acceptable diets for different population sets. The stigma attached to psychotherapy needs to be resolved and studies must evaluate the factors generated by the rapid socioeconomic and health transitions in economically developing country like India.

Social, political, financial, epidemiological and behavioral elements all add to the rising burden of NCDs and are key elements to counteractive action and control. The endless loop incorporates high risk behaviors; globalization that advances diets rich in calories, salt and fat; quick urbanization that adds to physical idleness and heftiness; business interests that advance unhealthy diets and beverages to youngsters; destitution and absence of education that deny individuals of chances and reasonableness of solid sustenance and medicinal services; financial instability that additionally decreases the interest in wellbeing and wellbeing frameworks; poor administration, corruption and absence of responsibility of governments and health systems (Reddy and Yusuf, 1998).

Prevention principles should be country and context specific and economically resource sensitive. Eliminating imbalances require tending to both behavioral and non-behavioral pathways. Health practices are not just individual choices, but instead are significantly molded by social and physical situations (Emmons, 2000; Graham, 1987; Lynch et al., 1997; Thorgeirsson and Kawachi, 2013) and sound practices are driven by a perplexing web of determinants. Figure 6 explains CVD burden in context with socioeconomic determinants. Hence equity, accessibility and socioeconomic inequalities should all be specifically addressed.

CVD are impacted by a wide range of issues in India like, economic development, urbanization of agrarian societies, environmental conditions and industrialization to name a few. Therefore, studies on social determinants of cardiovascular health should be encouraged to support and influence policy makers to develop strategies for different government departments that indirectly have important health implications modelling HiAP principles. Both opportunistic and focused health screening for risk behaviors and factors for CVD must be pursued by systematic and gradual risk reduction for long term care. Intensive care must be strengthened by enhancement of resuscitation skills, evidence based treatment protocols and cost-effective interventions at all levels of care. Strategies aimed at interventions across life span and implementing synergistic blends of population based policies based on both primary and primordial prevention which are based on socioeconomic status and lifestyle are likely to be more cost effective then sole reliance on secondary and tertiary level care providence (Reddy, 2002; Murray and Lopez, 1997).

These efforts can be mediated through essential socio cognitive constructs in developing a privileged community, a dynamic and spirited profession and a knowledgeable decision maker which, together, create the most effective recipe for primordial prevention both at a regional and national level.

\section{Gaps in Knowledge}

Is health still a commodity or a constitutional right in India? Who exactly is responsible for health? Is it only one organization, say MoHFW? State or Central government? Or the population themselves? Who is responsible 


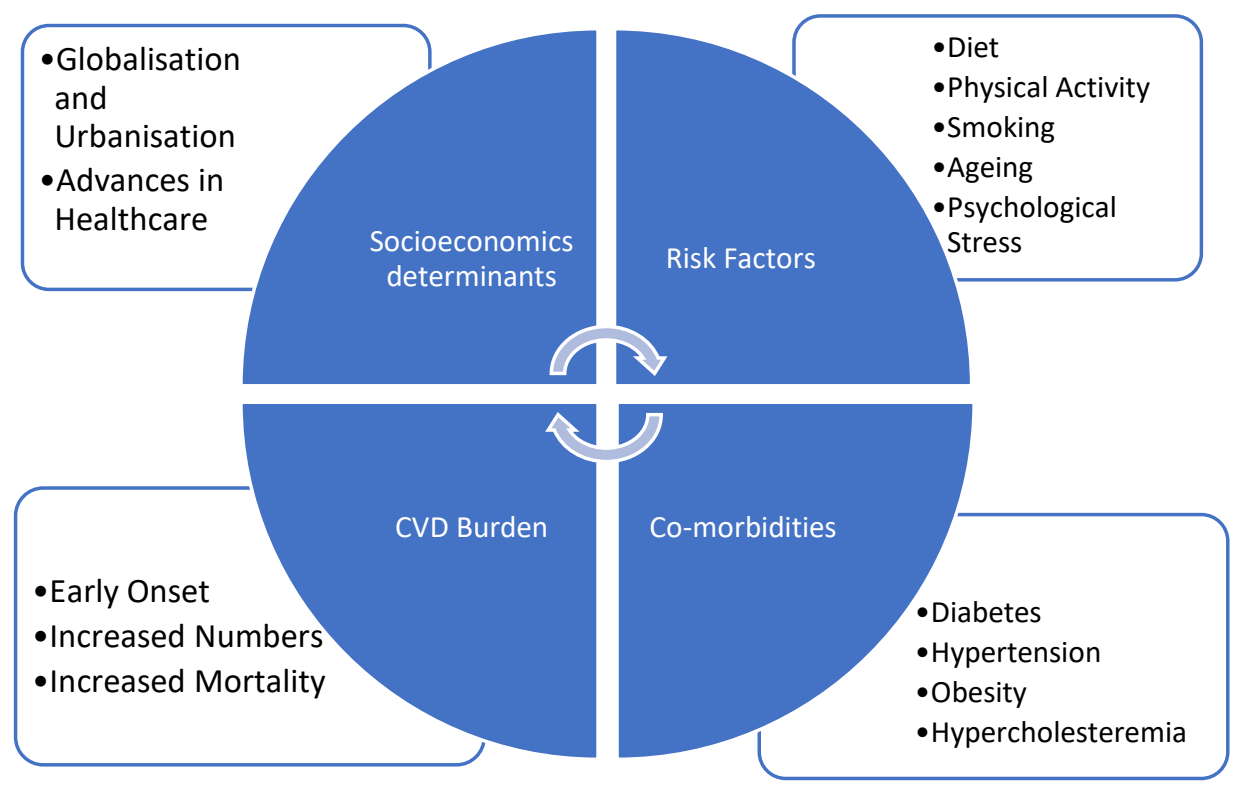

Figure 6. CVD burden explained in context with socioeconomic determinants (Global status report on Noncommunicable diseases, 2010)

for the disparities and inequalities in equity, efficiency, accessibility, service provision and adherence to evidence based best clinical practices along with technology diffusion? Are the patients given a chance to manage and be involved in their healthcare process? Significant variation exists between the strategic plans formulated and their implementation methods. Most of the plans fail to capture any inputs from both the caregivers and population. No data exists for the outcomes and objectives achieved. Majority of the policies fail to describe a clear implementation, monitoring and feedback process. The funding is not earmarked for a specific policy and can be allocated to other local area priority and needs assessments. There are no clinical initiatives to evaluate the efficacy of risk factor control and disease management.

Moreover, there is lack of integration of preventive and secondary care in multiple settings requiring a change implementation in task sharing and mode of care delivery affecting the quality of care being provided. A system of continuous evaluation, $360^{\circ}$ feedback and audit is required for developing cost effective interventions. There is an inherent urgency to establish a robust system for surveillance. The government policies lack the tooth to implement technology-based innovations in absence of a sizable research support strategy. India needs context specific policies in Indian setting for local adaptability and cost effectiveness.

\section{Future Perspectives and Capacity Building}

This research underscores the need for further studies on behavioral risk factors and should incorporate ecological, psychosocial and environmental attributes. Ethnographic approaches will increase our ability to explore cultural and other social aspects of cardiovascular health behavior. Key components to integrate "HiAP" into action are to confront gaps in current healthcare provisions by multi sectoral approach to Identify the context and testimony needed to plan, analyze, audit and support the structures and processes. Constant assessment, technological adaptations, engagement and evaluations are the building blocks for future capacity building in Indian healthcare.

\section{The Road Ahead}

World Health Assembly adopted a "Global Action Plan, 2020" and proposes all countries to effectively reduce the burden of NCDs and specially CVD (Yusuf et al., 2015; Global Action Plan for the Prevention and Control of NCDs 2013-2020, 2017). Recently the Union Cabinet of India has approved new 'National Health Policy', (National Health Policy, 2017) on 16 March 2017. While it still needs to be rolled out and is yet far from implementation stage, it promises to raise public health budget to $2.5 \%$ of gross domestic product (GDP) in a phased manner. This Plan looks at engaging the private sector as strategic partners to invest in promotional and preventive healthcare. It seeks to align inter sectoral policies with public health needs. NHP 2017 proposes to establish targets to reduce both disease prevalence and incidence, healthcare system performance evaluation, surveillance system strengthening and establishing national disease specific registries, by 2020. The primary aim is to strengthen, prioritize and promote good health through cross sectoral action, technologies, skill development programs, awareness generation, sustainable networks, medical pluralism, capacity building, financial protection 
strategies and health regulations. The policy advocates extensive use of digital tools and plans to set up "National Digital Health Authority (NDHA)" for regulations, development and deployment of digital health across the "continuum of care" through multifaceted and inclusive health services (National Health Policy, 2017).

\section{Summary Recommendations, Policy Development and Implementations - A HiAP based Approach}

The 'Action Plan' represents strategic implementation tools for any health policy to be effective at large but targets facilitation in inscribing the ambition of reconstructing national cardiovascular health through socioeconomic determinants of health. This mainly depends on a balanced investment in all core determinants and includes education to support individual efforts to prevent or control risk factors in line with the National Health policy of India, 2017. The five essential components of our recommendation (acronym-INDIA) are:

\section{I - Identify Organisations, Key Stakeholders their Roles and Responsibilities}

Identify main organizations (Ministry of health, Ministry of human resources specially Department of school and education, National digital health authority (NDHA) etc.), key stake holders (both public and private) and work with regional and global partners to share proficiencies and know-how in cardiovascular disease prevention. Define their roles and responsibilities. Bolster public health organizations, structure training events and scope, model guidelines and build assets for constant professional support for all involved partners.

\section{N- Needs Assessment and Prioritization}

Realistic needs assessment. Who will benefit and what resources do we have or need? Augment knowledge bedrock and systems to investigate key indices. Define benchmarks and principles for community wide health care. Improvise as required to satisfy long term continuity and adherence. Begin WHO recommended STEPwise approach and gradually implement it nationwide.

\section{D - Develop Goals and Objectives}

Develop India specific goals and objectives based on precede proceed model, in context with local needs and in line with constructs of SCT. Construct new policies and interventions in conformity with scientific advancement using social media tools pertinently in various settings for all age groups in a defined population which are comprehensive enough to have quantifiable impacts.

\section{I - Implement Strategy to Set Targets and Deadlines}

Execute intercessions apropos on an acceptable scale to allow rapid replication and dissemination applying concepts of precede proceed model. Promote social cognitive theory and its diffusion through interventions in multiple settings assuring complete convenience and pertinent use of services amongst populace with risk behaviors, factors or disease. More vigorous enforcement of the policies and legislated acts while continually developing and restructuring community-based care provision models.

\section{A - Assess Evaluate and Track Changes}

Promote an overall research environment to advance public health. Develop country specific "evidence-based health policies" and "health systems" for competent and dynamic allocation of health-care resources. Regular observation and audits to monitor implementation uptake and impact. Track the progress made and share it with community.

\section{CONCLUSION}

The research to date has been focused on risk prevention aspects of CVD rather than risk behavior modification through policy implementations. To advance heart health and reduce the CVD burden in India depends on the ability of healthcare systems and the government to get the grip on crucial social challenges to translate gains in measurable units. Control on CVD epidemic requires all stakeholders to brace, acknowledge and target social determinants linked to morbidity and mortality. Ingenious strategies are required to abort the advancing epidemic of cardiovascular diseases in developing nations. Our study elaborates on the CVD epidemic in India in context with socio economic determinants of risk factors and behavior and enumerates various measures undertaken by the GOI so far, for decreasing the global burden of cardiovascular diseases in India. While we acknowledge, and appreciate the efforts made by GOI we understand the complexities faced by policymakers in formulating national level strategies and their implementation nationwide due to the diverse milieu and sheer population size.

The recommendations aim to contribute to this growing area of interest by exploring possibilities of multisector handshake to address the social care and social determinants of health in population at large. A model wherein central government at the core tries to create a social diffusion of preventive strategies and policies with active 
community engagement. The incorporation of a systematic protocol based on our predefined conceptual frameworks to plan policy implementations designed to modify health behaviors will magnify and enhance Health related quality of life (HRQOL). This implementation would enable better allocation of resources, optimization of results and health equity for everyone. Only through the collective societal efforts we can decrease the burden of disease and the time to act is now.

\section{ABBREVIATIONS USED}

$\begin{array}{ll}\text { CVD } & \text { Cardiovascular disease } \\ \text { ACS } & \text { Acute coronary syndrome } \\ \text { DALY } & \text { Disability adjusted life years } \\ \text { WHO } & \text { World Health Organization } \\ \text { NCD } & \text { Non-communicable disease } \\ \text { LMIC } & \text { Low to middle income countries } \\ \text { IHD } & \text { Ischemic heart disease } \\ \text { HiAP } & \text { Health in all Policies } \\ \text { GOI } & \text { Government of India } \\ \text { HRQOL } & \text { Health related Quality of Life } \\ \text { NPCDCS } & \text { "National program for prevention and control of Cancer, Diabetes, Cardiovascular diseases and } \\ & \text { Stroke" } \\ \text { NCMH } & \text { National Commission on Macroeconomics and Health } \\ \text { NCDD } & \text { National Cardiovascular Disease Database } \\ \text { CCDC } & \text { Centre for Chronic Disease Control } \\ \text { NTCP } & \text { "National Tobacco control policy" } \\ \text { NTCC } & \text { "National Tobacco control cell" } \\ \text { MOHFW } & \text { "Ministry of Health and Family welfare" } \\ \text { HER } & \text { Electronic Health records } \\ \text { DHR } & \text { Department of Health Research } \\ \text { IDSP } & \text { "Integrated Disease Surveillance program" } \\ \text { HRIDAY } & \text { "Health related information dissemination among youth" } \\ \text { SHAN } & \text { "Student health action network" } \\ \text { IT } & \text { Information Technology } \\ \text { COP } & \text { Community outreach program } \\ \text { MYTRI } & \text { "Mobilizing youth for tobacco related initiatives in India" } \\ \text { COTPA } & \text { "Cigarette and other tobacco products Act" } \\ \text { RRT } & \text { Rapid response team } \\ \text { NIC } & \text { National informatics centre } \\ \text { SED } & \text { Socio Economic Determinants } \\ \text { SDOH } & \text { Socioeconomic determinants of health } \\ \text { SES } & \text { Socio Economic Status } \\ \text { UIDAI } & \text { "Unique Identification Authority of India" } \\ \text { NDHA } & \text { "National Digital Health Authority" } \\ & \end{array}$

\section{ACKNOWLEDGEMENT}

In the absence of disease specific registries pan India, epidemiological data is sourced from multiple sample studies conducted across the country. While every possible effort was undertaken to search the relevant literature and data we understand that publication bias might influence our research and understanding. GOI policies are current and updated as of date and have been verified from the official GOI website. Adherence and level of implementation of the existing GOI policies is beyond the scope of this project and hence was not evaluated.

This work has been undertaken under the guidance of Dr. Huseyin Naci, Assistant Professor of Health Policy at LSE Health, Department of Social policy, London School of Economics and in collaboration with European Society of Cardiology. 


\section{REFERENCES}

Anjana, R. M., Pradeepa, R., Deepa, M., Datta, M., Sudha, V., Unnikrishnan, R., Bhansali, A., Joshi, S. R., Joshi, P. P., Yajnik, C. S., Dhandhania, V. K., Nath, L. M., Das, A. K., Rao, P. V., Madhu, S. V., Shukla, D. K., Kaur, T., Priya, M., Nirmal, E., Parvathi, S. J., Subhashini, S., Subashini, R., Ali, M. K. and Mohan, V. (2011). ICMRINDIAB Collaborative Study Group. Prevalence of diabetes and prediabetes (impaired fasting glucose and/or impaired glucose tolerance) in urban and rural India: phase I results of the Indian Council of Medical ResearchINdia DIABetes (ICMR-INDIAB) study. Diabetologia, 54, 3022-3027. https://doi.org/10.1007/s00125-011$2291-5$

Anchala, R., Kannuri, N. K., Pant, H., Khan, H., Franco, O. H., Di Angelantonio, E. and Prabhakaran, D. (2014). Hypertension in India: a systematic review and meta-analysis of prevalence, awareness, and control of hypertension.J Hypertens., 32, 1170-1177. https://doi.org/10.1097/HJH.0000000000000146

Bandosz, P., O'Flaherty, M., Drygas, W., Rutkowski, M., Koziarek, J., Wyrzykowski, B., Bennett, K., Zdrojewski, T. and Capewell, S. (2012). Decline in mortality from coronary heart disease in Poland after socioeconomic transformation: modelling study. BMJ, 344, d8136. https://doi.org/10.1136/bmj.d8136

Bandura, A. (2002). Social Cognitive Theory in Cultural Context. Applied psychology: An international Review, 51(2), 269-290. https://doi.org/10.1111/1464-0597.00092

Bandura, A. (2004). Health Promotion by Social Cognitive Means. Health Education and Behavior, 31(2), 143-164. https://doi.org/10.1177/1090198104263660

Bhan, N., Srivastava, S., Agrawal, S., Subramanyam, M., Millett, C., Selvaraj, S. and Subramanian, S. V. (2012). Are socioeconomic disparities in tobacco consumption increasing in India? A repeated cross-sectional multilevel analysis. BMJ Open, 2. https://doi.org/10.1136/bmjopen-2012-001348

Bharathi, A. V., Sandhya, N. and Vaz, M. (2000). The development and characteristics of a physical activity questionnaire for epidemiological studies in urban middle class Indians. Indian J Med Res, 111, 95-102.

Bloom, D. E., Cafiero, E. T., Jané-Llopis, E., Abrahams-Gessel, S., Bloom, L. R., Fathima, S., Feigl, A. B., Gaziano, T., Mowafi, M., Pandya, A., Prettner, K., Rosenberg, L., Seligman, B., Stein, A. Z. and Weinstein, C. (2011). The Global Economic Burden of Noncommunicable Diseases. Geneva: World Economic Forum.

Bloom, D., Cafiero, E., Jane-Llopis, E. et al. (2011). The Global Economic Burden of Non-Communicable Diseases. Harvard School of Public Health and World Economic Forum, Boston, MA.

Braveman, P. and Tarimo, E. (2002). Social inequalities in health within countries: not only an issue for affluent nations. Soc Sci Med, 54, 1621-1635. https://doi.org/10.1016/S0277-9536(01)00331-8

Brunner, E. (2002). Stress mechanisms in coronary heart disease. In: Marmot M. Editor. Stress and the heart. London. BMJ Publishing, 181-199.

Capewell, S., Beaglehole, R., Seddon, M. and McMurray, J. (2000). Explanation for the decline in coronary heart disease mortality rates in Auckland, New Zealand, between 1982 and 1993. Circulation, 102, 1511-1516. https://doi.org/10.1161/01.CIR.102.13.1511

Census of India. (2001). Population Projection for India and States 2001-2026: Report of the Technical Group on Population Projections Constituted by the National Commission on Population. Office of Registrar General and census Commissioner, India.

Centre for Chronic Disease control. (2017). Available at: http://www.ccdcindia.org (Accessed 2 April 2017)

Chandola, T. (2001). Ethnic and class differences in health in relation to British South Asians: using the new National Statistics Socio-Economic Classification. Soc Sci Med., 52, 1285-1296. https://doi.org/10.1016/S0277-9536(00)00231-8

Chauhan, S. and Aeri, B. T. (2015). The rising incidence of cardiovascular diseases in India: Assessing its economic impact. J. Preventive Cardiology, 4(4).

Chow, C. K., Teo, K. K., Rangarajan, S., Islam, S., Gupta, R., Avezum, A., Bahonar, A., Chifamba, J., Dagenais, G., Diaz, R., Kazmi, K., Lanas, F., Wei, L., Lopez-Jaramillo, P., Fanghong, L., Ismail, N. H., Puoane, T., Rosengren, A., Szuba, A., Temizhan, A., Wielgosz, A., Yusuf, R., Yusufali, A., McKee, M., Liu, L., Mony, P. and Yusuf, S. (2013). PURE (Prospective Urban Rural Epidemiology) Study investigators. Prevalence, awareness, treatment, and control of hypertension in rural and urban communities in high-, middle-, and lowincome countries. JAMA, 310, 959-968. https:// doi.org/10.1001/jama.2013.184182

COTPA. (2017). Ministry of Health and Family Welfare, Government of India: Available at http:/ / mohfw.gov.in/WriteReadData/1892s/COTPA.pdf (Accessed 2 February 2017)

Danaei, G., Finucane, M. M., Lin, J. K., Singh, G. M., Paciorek, C. J., Cowan, M. J., Farzadfar, F., Stevens, G. A., Lim, S. S., Riley, L. M. and Ezzati, M. (2011). Global Burden of Metabolic Risk Factors of Chronic Diseases Collaborating Group (Blood Pressure). National, regional, and global trends in systolic blood pressure since 1980: systematic analysis of health examination surveys and epidemiological studies with 786 country-years and 5.4 million participants. Lancet, 377, 568-577. https:// doi.org/10.1016/S0140-6736(10)62036-3 
Dhaka, V., Gulia, N., Ahlawat, K. S. and Khatkar, B. S. (2011). Trans fats-sources, health risks and alternative approach - a review. J Food Sci Technol., 48, 534-541. https:// doi.org/10.1007/s13197-010-0225-8

Eckel, R. H., Grundy, S. M. and Zimmet, P. Z. (2005). The metabolic syndrome. Lancet, 365, 1415-1428. https://doi.org/10.1016/S0140-6736(05)66378-7

Electronic Health Records (EHR) Standards. (2017). Ministry of Health and Family Welfare, Government of India. Available at: http://www.mohfw.nic.in/sites/default/files/17739294021483341357_1.pdf

Emmons, K. M. (2000). Health behaviors in a social context. In: Berkman, L.F., Kawachi, I., eds. Social epidemiology. New York: Oxford University Press, 242-66.

Enas, E. A., Singh, V., Munjal, Y. P., Gupta, R., Patel, K. C. and Bhandari. S. et al. (2009). Recommendations of the second Indo-US health summit on prevention and control of cardiovascular disease among Asian Indians. Indian Heart J., 61, 165-274.

Engelgau, A. K. M and Mahal, A. (2014). The household-level economic burden of heart disease in India. Tropical Medicine and International Health, 19(5), 581-591. https:// doi.org/10.1111/tmi.12281

Ford, E. S., Ajani, U. A., Croft, J. B., Critchley, J. A., Labarthe, D. R., Kottke, T. E., Giles, W. H. and Capewell, S. (2007). Explaining the decrease in U.S. deaths from coronary disease, 19802000. N Engl J Med., 356, 23882398. https://doi.org/10.1056/NEJMsa053935

Ghaffar, A., Reddy, K. S. and Singhi, M. (2004). Burden of Noncommunicable diseases in South Asia. BMJ, 328, 807-10. https:// doi.org/10.1136/bmj.328.7443.807

GIA. (2017). Department of health research. Ministry of Health and Family Welfare, Government of India. Available at: http://www.dhr.gov.in/schemes

Giovino, G. A., Mirza, S. A., Samet, J. M., Gupta, P. C., Jarvis, M. J., Bhala, N., Peto, R., Zatonski, W., Hsia, J., Morton, J., Palipudi, K. M. and Asma, S. (2012). GATS Collaborative Group. Tobacco use in 3 billion individuals from 16 countries: an analysis of nationally representative cross-sectional household surveys. Lancet, 380, 668-679. https://doi.org/10.1016/S0140-6736(12)61085-X

Global status report on Noncommunicable diseases. (2010). WHO. Available at http://www.who.int/nmh/publications/ncd_report_full_en.pdf

Global Action Plan for the Prevention and Control of NCDs 2013-2020. (2017). WHO Available at: http:/ / www.who.int/ cardiovascular_diseases/15March2013UpdatedRevisedDraftActionPlan.pdf

Glymour, M. M., Clark, C. R. and Patton, K. K. (2014). Socioeconomic Determinants of Cardiovascular Disease: Recent Findings and Future Directions. Curr. Epidemiol Rep., 1, 89-97. https://doi.org/10.1007/s40471-0140010-8

Goyal, A. and Yusuf, S. (2006). The burden of cardiovascular disease in the Indian subcontinent. Indian Journal of Medical Research, 124, 235-244.

Graham, H. (1987). Women's smoking and family health. Soc Sci Med, 25(1), 47-56. https:/ / doi.org/10.1016/02779536(87)90206-1

Green, L. W. and Kreuter, M. W. (2005). Health Program Planning: An Educational and Ecological Approach. New York: McGraw-Hill.

Green, L. W. and Kreuter, M. W. (2015). Precede-Proceed. Available at: https://www.lgreen.net/precede.htm (Accessed 13 December 2016)

Gupta, R., Gupta, V. P. and Ahluwalia, N. S. (1994). Educational status, coronary heart disease and coronary risk factor prevalence in a rural population of India. BMJ, 309, 1332-1336. https://doi.org/10.1136/bmj.309.6965.1332

Gupta, R. and Gupta, V. P. (1998). Lessons for prevention from a coronary heart disease epidemiology study in western India. Curr Science, 74, 1074-1077.

Gupta, R., Joshi, P. and Mohan, V. (2000). Epidemiology and Causation of coronary heart disease and stroke in India. Heart, 94, 16-26. https:// doi.org/10.1136/hrt.2007.132951

Gupta, R., Gupta, V. P., Sarna, M., Prakash, H., Rastogi, S. and Gupta, K. D. (2003). Serial epidemiological surveys in an urban Indian population demonstrate increasing coronary risk factors among the lower socioeconomic strata. J Assoc Physicians India, 51, 470-477.

Gupta, R. (2004). Burden of coronary heart disease in India. Indian Heart J., 57, 632-8. https://doi.org/10.1016/j.ijcard.2003.11.003

Gupta, R., Deedwania, P. C., Gupta, A., Rastogi, S., Panwar, R. B. and Kothari, K. (2004). Prevalence of metabolic syndrome in an urban Indian population. Int J Cardiol, 97, 257-261.

Gupta, I., Kandamuthan, S. and Upadhyaya, D. (2006). Economic impact of cardiovascular diseases in India. Institute of Economic Growth, University of Delhi, New Delhi, India.

Gupta, R., Guptha, S., Agrawal, A., Kaul, V., Gaur, K., Gupta, V. P. (2008). Secular trends in cholesterol lipoproteins and triglycerides and prevalence of dyslipidemias in an urban Indian population. Lipids Health Dis., 7, 40. https://doi.org/10.1186/1476-511X-7-40 
Gupta, R. and Gupta, K. D. (2009). Coronary Heart Disease in Low Socioeconomic Status Subjects in India: An Evolving Epidemic. Indian Heart Journal, 61, 358-367.

Gupta, R., Sharma, K. K., Gupta, A., Agrawal, A., Mohan, I., Gupta, V. P., Khedar, R. S. and Guptha, S. (2012). J Assoc Physicians India, 60, 11-16. https:// doi.org/10.4330/wjc.v4.i4.112

Gupta, R., Guptha, S., Sharma, K. K. and Gupta, A. (2012). Deedwania P. Regional variations in cardiovascular risk factors in India: India heart watch. World J Cardiol, 4, 112-120.

IDF Diabetes Atlas. (2017). 7th ed. International Diabetes Federation; English. Available at: http://www.diabetesatlas.org/

IHME. (2017). Institute for Health Metrics and Evaluation. University of Washington. Available at: https:/ / healthdata.org (Accessed 31 March 2017)

Indian Council of Medical Research. (2017). Nutrient Requirements and Recommended Dietary Allowances for Indians. A Report of the Expert Group of the Indian Council of Medical Research. New Delhi, India. Indian Council of Medical Research. Available at: http://icmr.nic.in/final/rda-2010.pdf (Accessed 20 March 2017)

Indrayan, A. (2005). Forecasting Vascular Disease Cases and Associated Mortality in India". Burden of disease in India, National Commission on Macroeconomics and Health, Ministry of Health and Family Welfare. Government of India, New Delhi, India.

Integrated Disease Surveillance program. (2017). National centre for disease control. Directorate General of Health Services. Available at: http:/ / www.idsp.nic.in/

Joshi, S. R., Anjana, R. M., Deepa, M., Pradeepa, R., Bhansali, A., Dhandania, V. K., Joshi, P. P., Unnikrishnan, R., Nirmal, E., Subashini, R., Madhu, S. V., Rao, P. V., Das, A. K., Kaur, T., Shukla, D. K. and Mohan, V. (2014). ICMR-INDIAB Collaborative Study Group. Prevalence of dyslipidemia in urban and rural India: the ICMRINDIAB study. PLoS One, 9:e96808. https://doi.org/10.1371/journal.pone.0096808

Kearney, P. M., Whelton, M., Reynolds, K., Muntner, P., Whelton, P. K. and He, J. (2005). Global burden of hypertension: analysis of worldwide data. Lancet, 365, 217-223. https://doi.org/10.1016/S01406736(05)70151-3

Kutty, V. R., Thankappan, K. R., Kannan, K. P. and Aravindan, K. P. (1993). How socioeconomic status affects birth and death rates in rural Kerala, India: results of a health study. Int J Health Serv., 23, 373-386. https://doi.org/10.2190/9N4P-F1L2-13HM-CQVW

Lal, P. G., Wilson, N. C. and Gupta, P. C. (2012). Attributable deaths from smoking in last 100 years in India. Curr Sci., 103, 1085-1090.

Leeder, S., Raymond, S., Greenberg, H., Liu, H. and Esson, K. (2004). A Race against Time: The Challenge of Cardiovascular Disease in Developing Countries. Columbia University Press, New York, NY.

Lynch, J. W., Kaplan, G. A. and Salonen, J. T. (1997). Why do poor people behave poorly? Variation in adult health behaviours and psychosocial characteristics by stages of the socioeconomic lifecourse. Soc Sci Med., 44(6), 809_ 19. https://doi.org/10.1016/S0277-9536(96)00191-8

Mahal, A. (2005). Estimation and Causal Analysis. Overview based on 'Choosing Investments in Health' for the National Commission on Macroeconomics and Health. NCMH background papers- Burden of Disease in India.

Mahal, A., Karan, A. and Engelgau, M. (2010). Economic Implications of Non-communicable Disease for India. The World Bank, Washington, DC.

Ministry of Health and Family Welfare, Government of India. (2017). Available at: http://mohfw.nic.in/index1.php?lang=1\&level=3\&sublinkid=3627\&lid=2194 (Accessed 25 March 2017) Additional report available at: http://mohfw.gov.in/WriteReadData/c08032016/78963256452123365785.pdf

Misra, A., Sharma, R., Pandey, R. M. and Khanna, N. (2001). Adverse profile of dietary nutrients, anthropometry and lipids in urban slum dwellers of northern India. Eur $J$ Clin Nutr., 55, 727-734. https://doi.org/10.1038/sj.ejcn.1601214

Misra, A., Pandey, R. M., Devi, J. R., Sharma, R., Vikram, N. K. and Khanna, N. (2001). High prevalence of diabetes, obesity and dyslipidaemia in urban slum population in northern India. Int J Obes, 25, 1722-1729. https://doi.org/10.1038/sj.ijo.0801748

Mohan, V. et al. (2017). ICMR INdia DIABetes INDIAB Study. Final report. Available at: http://icmr.nic.in/final/indiab/ICMR\%20INDIAB\%20PHASE\%20I\%20FINAL\%20REPORT.pdf

Monteiro, C. A., Moura, E. C., Conde, W. L. and Popkin, B. M. (2004). Socioeconomic status and obesity in adult populations of developing countries: a review. Bull WHO, 82, 940-946.

MPOWER Brochure. WHO. (2017). http://www.who.int/tobacco/mpower/publications/brochure_2013/en/

MRHRU. (2017). Department of health research. Ministry of Health and Family Welfare, Government of India. Available at: http://www.dhr.gov.in/schemes

Murray, C. J. L. and Lopez, A. D. (1997). Alternative projections of mortality and disability by cause 1990-2020: Global burden of disease study. Lancet, 349, 1498-1504. https://doi.org/10.1016/S0140-6736(96)07492-2

National Family health survey 3. (2017). Available at: http://rchiips.org/nfhs/nfhs3.shtml 
National Tobacco Control Program. (2017). Ministry of Health and Family Welfare, Government of India: Available at: https://www.nhp.gov.in/national-tobacco-control-programme1_pg (Accessed 2 April 2017)

National Rural Health Mission. (2017). Available at: http://nrhm.gov.in/ (Accessed 30 March 2017)

National Programme for Health Care of the Elderly (NPHCE). (2017). Available at: http://mohfw.gov.in/majorprogrammes/other-national-health-programmes/national-programme-health-care-elderlynphce (Accessed 2 Feb 2017)

National Health Policy. (2017). Ministry of Health and Family welfare. Available at: http://mohfw.nic.in/showfile.php?lid=4275

NHP. (2002). Available at: https://www.nhp.gov.in/sites/default/files/pdf/NationaL_Health_Pollicy.pdf

NPCDCS. (2017). Available at: https://www.nhp.gov.in/national-programme-for-prevention-and-control-ofc_pg (Accessed 2 February 2017)

Popkin, B., Horton, S., Kim, S., Mahal, A. and Shuigao, J. (2001). Trends in diet, nutritional status, and diet-related non-communicable diseases in China and India: the economic costs of the nutrition transition. Nutrition Reviews, 59, 379-390. https://doi.org/10.1111/j.1753-4887.2001.tb06967.x

Porter, C. M. (2016). Revisiting Precede-Proceed: A leading model for ecological and ethical health promotion. Health Education, 75(6), 753-764. https://doi.org/10.1177/0017896915619645

Prabhakaran, D., Shah, P., Chaturvedi, V., Ramakrishnan, L., Manhapra, A. and Reddy, K. S. (2005). Cardiovascular risk factor prevalence among men in a large industry of northern India. The National Medical Journal of India, 18, 59-65.

Prabhakaran, D., Jeemon, P. and Reddy, K. S. (2013). Poverty and cardiovascular disease in India: Do we need more evidence for action? International Journal of Epidemiology, 1-5. https:// doi.org/10.1093/ije/dyt119

Prabhakaran, D., P. and Jeemon, A. R. (2016). Cardiovascular Disease in India: Current Epidemiology and Future Directions. Circulation, 133(16), 1605-20. https://doi.org/10.1161/CIRCULATIONAHA.114.008729

Ramachandran, A., Snehalatha, C., Satyavani, K., Sivasankari, S. and Vijay, V. (2003). Metabolic syndrome in urban Asian Indians adults: a population study using modified ATP III criteria. Diab Res Clin Pract, 60, 199-204. https:/ / doi.org/10.1016/S0168-8227(03)00060-3

Ramachandran, P. (2006). The Double Burden of Malnutrition in India. Food and Agriculture Organization. Available at: ftp://ftp.fao.org/docrep/fao/009/a0442e/a0442e01.pdf

Reddy, K. S. and Yusuf, S. (1998). Emerging Epidemic of Cardiovascular Disease in Developing Countries. Circulation, 97, 596-601. https://doi.org/10.1161/01.CIR.97.6.596

Reddy, K. S. (2002). Cardiovascular diseases in the developing countries: dimensions, determinants, dynamics and directions for public health action. Public Health Nutrition, 5(1A), 231-237. https://doi.org/10.1079/PHN2001298

Reddy, K. S. and Katan, M. B. (2004). Diet, nutrition and the prevention of hypertension and cardiovascular diseases. Public Health Nutrition, 7, 167-186. https:/ / doi.org/10.1079/PHN2003587

Reddy, K. S., Perry, C. L., Stigler, M. H. and Arora, M. (2006). Differences in tobacco use among young people in urban India by sex, socioeconomic status, age, and school grade: assessment of baseline survey data. Lancet, 367, 589-594. https:// doi.org/10.1016/S0140-6736(06)68225-1

Sachdeva, S., Sachdev, T. R. and Sachdeva, R. (2013). Increasing fruit and vegetable consumption: challenges and opportunities. Indian J Community Med., 38, 192-197. https:/ / doi.org/10.4103/0970-0218.120146

Tarry-Adkins, J. L. and Ozanne, S. E. (2011). Mechanisms of early life programming: current knowledge and future directions. Am J Clin Nutr., 94(6 suppl), 1765S-1771S. https://doi.org/10.3945/ajcn.110.000620

Thorgeirsson, T. and Kawachi, I. (2013). Behavioral economics: merging psychology and economics for lifestyle interventions. Am J Prev Med., 44(2), 185-189. https://doi.org/10.1016/j.amepre.2012.10.008

Unal, B., Critchley, J. A. and Capewell, S. (2004). Explaining the decline in coronary heart disease mortality in England and Wales between 1981 and 2000. Circulation, 109, 1101-1107. https://doi.org/10.1161/01.CIR.0000118498.35499.B2

Union budget 2014-2015. (2017). Available at: http://www.indiabudget.nic.in (Accessed 20 February 2017)

Unique Identification Authority of India. (2017). Available at: www.uidai.gov.in

Vasan, S. K. and Thomas, N. (2012). Developmental origins of adult metabolic disease: the Indian scenario, driving toward a unified hypothesis. Indian J Endocrinol Metab., 16, 493-495. https://doi.org/10.4103/2230-8210.97990

Victora, C. G., Adair, L., Fall, C., Hallal, P. C., Martorell, R., Richter, L. and Sachdev, H. S. (2008). Maternal and Child Undernutrition Study Group. Maternal and child undernutrition: consequences for adult health and human capital. Lancet, 371, 340-357. https:// doi.org/10.1016/S0140-6736(07)61692-4

WHO Framework for Action. (2007). Everybody`s business: strengthening health systems to improve health outcomes. Geneva, World Health Organization, 2007.

WHO. (2011). Global Atlas on Cardiovascular Disease Prevention and Control. Available from: www.who.int/cardiovascular_diseases/publications/atlas_cvd/en 
WHO. (2014). Health in All Policies (HiAP) Framework for Country Action. Available at: http://www.who.int/cardiovascular_diseases/140120HPRHiAPFramework.pdf (Accessed 31 March 2017)

World Health Organization (WHO). (2010). Package of Essential Noncommunicable (PEN) disease interventions for primary bealth care in low-resource settings.

World Health Assembly (WHA). (2008). Action Plan for the Global Strategy for the Prevention and Control of Noncommunicable Diseases (NCDs). Geneva, World Health Organization, 2008 (WHA A61/8).

Yusuf, S., Hawken, S., Ounpuu, S., Dans, T., Avezum, A., Lanas, F. et al. and the INTERHEART Study Investigators. (2004). Effect of potentially modifiable risk factors associated with myocardial infarction in 52 countries (The INTERHEART Study): Case control study. Lancet, 364, 937-952. https://doi.org/10.1016/S0140-6736(04)17018-9

Yusuf, S., Wood, D., Ralston, J. and Reddy, K. S. (2015). The World Heart Federation's vision for worldwide cardiovascular disease prevention. Lancet, 386, 9991, 399-402. https://doi.org/10.1016/S0140-6736(15)602653 